\title{
The Impact of Virtual Interviews on the Geographic Distribution of Ophthalmology Match Results in the 2020-2021 Cycle
}

\author{
Chandruganesh Rasendran, MD ${ }^{1}$ Sarah Rahman, BA ${ }^{2}$ Uthman Younis, BA ${ }^{3}$ Raoul Wadhwa, BA \\ Manasvee Kapadia, $\mathrm{MD}^{1}$ Jonathan H. Lass, $\mathrm{MD}^{1} \quad$ Linda H. Ohsie-Bajor, MD ${ }^{1}$
}

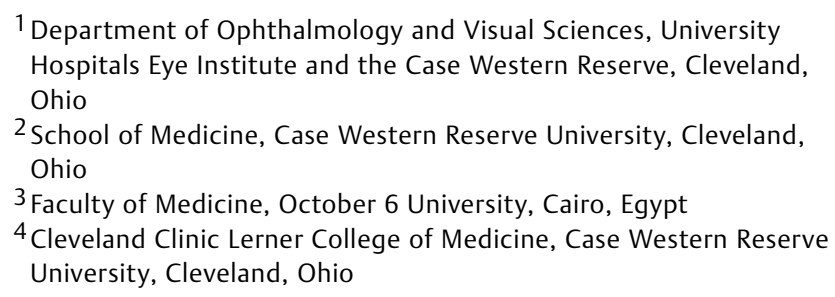

${ }^{2}$ School of Medicine, Case Western Reserve University, Cleveland, Ohio

${ }^{3}$ Faculty of Medicine, October 6 University, Cairo, Egypt

${ }^{4}$ Cleveland Clinic Lerner College of Medicine, Case Western Reserve University, Cleveland, Ohio

J Acad Ophthalmol 2021;13:e242-e246.
Address for correspondence Linda H. Ohsie-Bajor, MD, University Hospitals Cleveland Medical Center, 11100 Euclid Ave, Cleveland, OH 44106 (e-mail: Linda.Ohsie-Bajor@UHhospitals.org).

\section{Abstract \\ Keywords \\ - virtual interviews \\ - COVID-19 \\ - visiting student \\ - applicants \\ - ophthalmology residency}

Background Instead of the traditional in-person interviews, the 2020 to 2021 ophthalmology application cycle was conducted with virtual interviews due to coronavirus disease 2019 (COVID-2019). Little is known about differences between the results of this application cycle with previous years.

Objectives The aim of this study was to determine the effect of virtual interviews on the geographic distribution of matched ophthalmology residency applicants.

Methods Information was collected on the medical school location and matched residency program location for 2020 to 2021 applicants as well as applicants during the 2016 to 2017,2017 to 2018, and 2018 to 2019 cycles from publicly available Web sites. Pearson chi-squared tests were conducted to determine whether there was a significant difference in the proportion of applicants matching in the same region, state, and institution as their medical schools in the 2020 to 2021 interview cycle when compared with past cycles.

Results Three-hundred seventy-five applicants from 2020 to 2021 and 1,190 applicants from 2016 to 2019 application cycles were analyzed. There was no difference in the type of medical school attended (allopathic vs. osteopathic vs. international medical graduate) $(p=0.069)$, the likelihood of attending a residency program in the same region as the home medical school (54\% for $2020-2021$ vs. $57 \%$ for 2016 2019 applicants, $p=0.3$ ), and the likelihood of attending a residency program in the same state as the home medical school ( 31 vs. $28 \%, p=0.2$ ). There was a higher likelihood of applicants during the 2020 to 2021 cycle matching at a residency program affiliated with their home medical school than previous cycles ( 23 vs. $18 \%, p=0.03$ ). received

July 21,2021

accepted after revision

October 12, 2021
DOI https://doi.org/ $10.1055 / \mathrm{s}-0041-1740325$. ISSN 2475-4757.

\footnotetext{
(C) 2021. The Author(s).

This is an open access article published by Thieme under the terms of the Creative Commons Attribution-NonDerivative-NonCommercial-License, permitting copying and reproduction so long as the original work is given appropriate credit. Contents may not be used for commercial purposes, or adapted, remixed, transformed or built upon. (https://creativecommons.org/ licenses/by-nc-nd/4.0/) Thieme Medical Publishers, Inc., 333 Seventh Avenue, 18th Floor, New York, NY 10001, USA
} 
Conclusions Virtual interviews did not increase the likelihood of medical students staying in the same region or state as their medical school, while there was a higher likelihood of applicants matching at residency programs at institutions affiliated with their medical schools. A hybrid approach to maintain geographic diversity of applicants' final residency programs involving virtual interviews with the addition of inperson away rotations is suggested.

With the advent of the coronavirus disease 2019 (COVID-19) pandemic, the Association of University Professors of Ophthalmology (AUPO) recommended that applicants for the 2020 to 2021 academic year undergo virtual interviews with no in-person away rotations unless applicants had no home ophthalmology program. ${ }^{1}$ Previously, applicants were invited to interview in-person at each residency program and had the opportunity to participate in rotations at other institutions. During the 2020 to 2021 application cycle, applicants and program directors alike faced uncertainty about the future format of residency interviews, that is, whether it should stay virtual or transition back to in-person. ${ }^{2}$ There were concerns regarding potential difficulties for medical students to match at ophthalmology residency programs that were geographically distant from their home institution. The AUPO has announced that the 2021 to 2022 ophthalmology application cycle will continue to have virtual interviews, although students are now allowed to participate in one away rotation. ${ }^{3}$ The purpose of this study was to evaluate whether virtual interviews affected the geographic spread of matched applicants' final residency programs when compared with past years with in-person interviewing, and provide insight into the effects of virtual interviews for future application cycles.

\section{Methods}

A publicly accessible spreadsheet widely used by ophthalmology applicants during the 2020 to 2021 interview cycle was used to obtain information regarding applicants' medical schools and the residency programs at which they matched. Each residency program Web site was then visited to record information about current postgraduate year 2 (PGY-2) to PGY-4 residents' home medical schools (20162017, 2017-2018, and 2018-2019 interview cycles). The type of medical school (allopathic (MD), osteopathic (DO), or International Medical Graduate (IMG)) and location of each applicant's medical school were recorded. Each applicant's medical school and residency program were individually assessed to determine if a medical student matched at a residency program affiliated with their home institution. The location of medical schools and residency programs were then assessed together as regions as defined by the United States Census Bureau (-Supplementary Table S1, available online only $>)^{4}$

Baseline characteristics of the study population were characterized in aggregate and stratified by 2020 to 2021 and past cycles. Pearson chi-squared tests were conducted to determine whether there was a significant difference in the proportion of applicants matching in the same region, state, and institution as their medical schools in the 2020 to 2021 interview cycle when compared with past cycles. A twosided $\alpha$ of 0.05 was used. The $\mathrm{R}$ programming language was

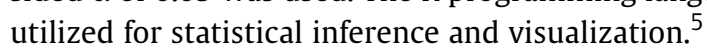

\section{Results}

There were a total of 2019 ophthalmology resident positions examined including 500 incoming residents in 2021 who participated in the 2020 to 2021 virtual interview cycle, and 1,519 applicants from the 2016 to 2019 application cycles who had traditional in-person interviews. Three-hundred seventyfive $(75.0 \%)$ of the incoming residents in 2021 self-reported their medical school and medical school affiliation was able to be gathered for 1,190 (78.3\%) of the existing categorical residents. Between the two cohorts, there was no difference in the type of medical school attended (allopathic vs. osteopathic vs. international graduate) $(p=0.07)$, the likelihood of attending a residency program in the same region as the home medical school (202/375 [54\%] in the 2020-2021 cycle; $674 / 1190$ [57\%] in the 2016-2019 cycles, $p=0.3$ ), or the likelihood of attending a residency program in the same state as the home medical school (119/375 [31\%] vs. 343/1,190 [28\%], $p=0.2$ ) ( Table 1). There was a higher likelihood of applicants during the 2020 to 2021 cycle matching at a residency program affiliated with their home medical school than previous cycles ( 23 vs. $18 \%, p=0.03$ ). When comparing 2020 to 2021 and 2016 to 2019 applicants by region, similar proportions of medical students in each region stayed in the same region for residency (-Fig. $\mathbf{1 A}$ and $\mathbf{B}$ ).

When further splitting the entire cohort by each home medical school region, there were no statistically significant differences between applicants during the 2020 to 2021 applicant cycle and applicants during past years for matching in the same region or matching at the home program (Midwest: $p=0.9$ for same region and $p=0.14$ for matching at home program; South: $p=0.2$ for same region and $p=0.06$ for home program; Northeast: $p=0.7$ and $p=0.05$, respectively; West: $p=0.4$ and $p=0.3$, respectively). For matched applicants that attended medical schools located in the South, residents were less likely to have attended osteopathic medical schools during the 2020 to 2021 applicant cycle when compared with past cycles (0\% osteopathic in $2020-$ 2021 vs. $3.9 \%$ osteopathic in past cycles, $p=0.03$ ). 
The Impact of Virtual Interviews on the Geographic Distribution of Ophthalmology Match Results in the 2020-2021

Table 1 Characteristics of ophthalmology residency applicants both in aggregate and stratified by applicant year cycle (2020 vs. 2016-2019)

\begin{tabular}{|c|c|c|c|c|c|}
\hline \multirow[b]{2}{*}{ Characteristic } & \multicolumn{2}{|c|}{ Overall cohort } & \multicolumn{3}{|c|}{ By applicant year } \\
\hline & $n$ & $n=2,019^{a}$ & $2021, n=500^{a}$ & 2016-2019, $n=1,322^{\mathrm{a}}$ & $p$-Value ${ }^{b}$ \\
\hline Medical school classification & 1,636 & & & & 0.069 \\
\hline Allopathic & & $1,522(93 \%)$ & $366(96 \%)$ & $1,148(92 \%)$ & \\
\hline Osteopathic & & $52(3.2 \%)$ & $9(2.3 \%)$ & $43(3.5 \%)$ & \\
\hline International Medical Graduate & & $62(3.8 \%)$ & $8(2.1 \%)$ & $54(4.3 \%)$ & \\
\hline Region of residency program & 2,019 & & & & 0.9 \\
\hline Northeast & & $533(26 \%)$ & $131(26 \%)$ & $357(27 \%)$ & \\
\hline Midwest & & $487(24 \%)$ & $121(24 \%)$ & $339(26 \%)$ & \\
\hline South & & $718(36 \%)$ & $180(36 \%)$ & $453(34 \%)$ & \\
\hline West & & $281(14 \%)$ & $68(14 \%)$ & $173(13 \%)$ & \\
\hline Region of medical school & 1,573 & & & & 0.4 \\
\hline Northeast & & $441(28 \%)$ & $105(28 \%)$ & $336(28 \%)$ & \\
\hline Midwest & & $413(26 \%)$ & $103(27 \%)$ & $306(26 \%)$ & \\
\hline South & & $562(36 \%)$ & $123(33 \%)$ & $437(37 \%)$ & \\
\hline West & & $157(10.0 \%)$ & $44(12 \%)$ & $111(9.3 \%)$ & \\
\hline Residency and medical school region match & 1,573 & $880(56 \%)$ & $202(54 \%)$ & $674(57 \%)$ & 0.3 \\
\hline Residency and medical school state match & 1,636 & $464(28 \%)$ & $119(31 \%)$ & $343(28 \%)$ & 0.2 \\
\hline Match at home program & 1,661 & $311(19 \%)$ & $87(23 \%)$ & $224(18 \%)$ & 0.026 \\
\hline
\end{tabular}

Bold $p$-values indicate a significant difference in distribution of values between the two applicant year groups.

${ }^{a} n(\%)$.

bearson chi-squared test.

\section{Discussion}

There were many uncertainties regarding the effect of virtual interviews on the final residency program positions for applicants to ophthalmology residency. This study reports that the virtual format for interviews did not alter the likelihood of medical students staying in the same region or state as their medical school. However, during this past application cycle, there was a higher likelihood of ophthalmology applicants matching at residency programs at institutions affiliated with their medical schools. This difference was not found when analyzing specific regions for residency programs, which may be due to the smaller sample sizes of applicants in these subset analyses. Lastly, there was no difference in the proportion of matched applicants that attended osteopathic or international medical schools, suggesting that these groups were not adversely affected by the virtual interview format.

For medical students, in-person interviews and away rotations place a significant financial burden on applicants' shoulders. The average fourth-year medical student spent an average of $\$ 3,422$ for interview travel costs and $\$ 1,839$ for an away rotation. ${ }^{6}$ The average ophthalmology applicant spent $\$ 5704$ during the 2018 to 2019 application cycle. ${ }^{7}$ They also did not feel they were able to reduce costs by limiting the number of applications or interview offers they accepted. ${ }^{7}$ For each interview, an applicant spent $\$ 200$ to 300 on transportation costs, $\$ 100$ to 200 on housing expenses, and $\$ 50$ on other expenses. These costs were mitigated during the virtual interview cycle and accumulates over the average number of interviews attended by most applicants. However, in-person interviews and away rotations enable applicants to form important social connections with both faculty and potential future coresidents, as well as allow them to assess overall culture, fit, and camaraderie of the program. ${ }^{2,8,9}$ Many applicants during the cycle favored inperson interviews with virtual interviews as a possible option. Medical students that desired a residency position in more distant geographic locations from their home medical school were more likely to support in-person interviews. ${ }^{8}$ The majority of medical students felt that virtual interviews would make them appear to be a less serious or less dedicated applicant as compared with someone who attended an interview in-person. This viewpoint was more pervasive for applicants into surgical subspecialties. For applicants into ophthalmology, only $11.1 \%$ of applicants were supportive of virtual interviews as a viable alternative format. ${ }^{8}$ Although the present study did not report an increased likelihood of applicants staying in the same geographic region, there was an increased chance of matching at a residency program affiliated with the same medical school. This may be due to the extensive in-person connections formed by the medical students during rotations at the home program, which were not able to be established at other programs during this application cycle. These in-person connections that can be developed by working with faculty and residents during 


\section{A}

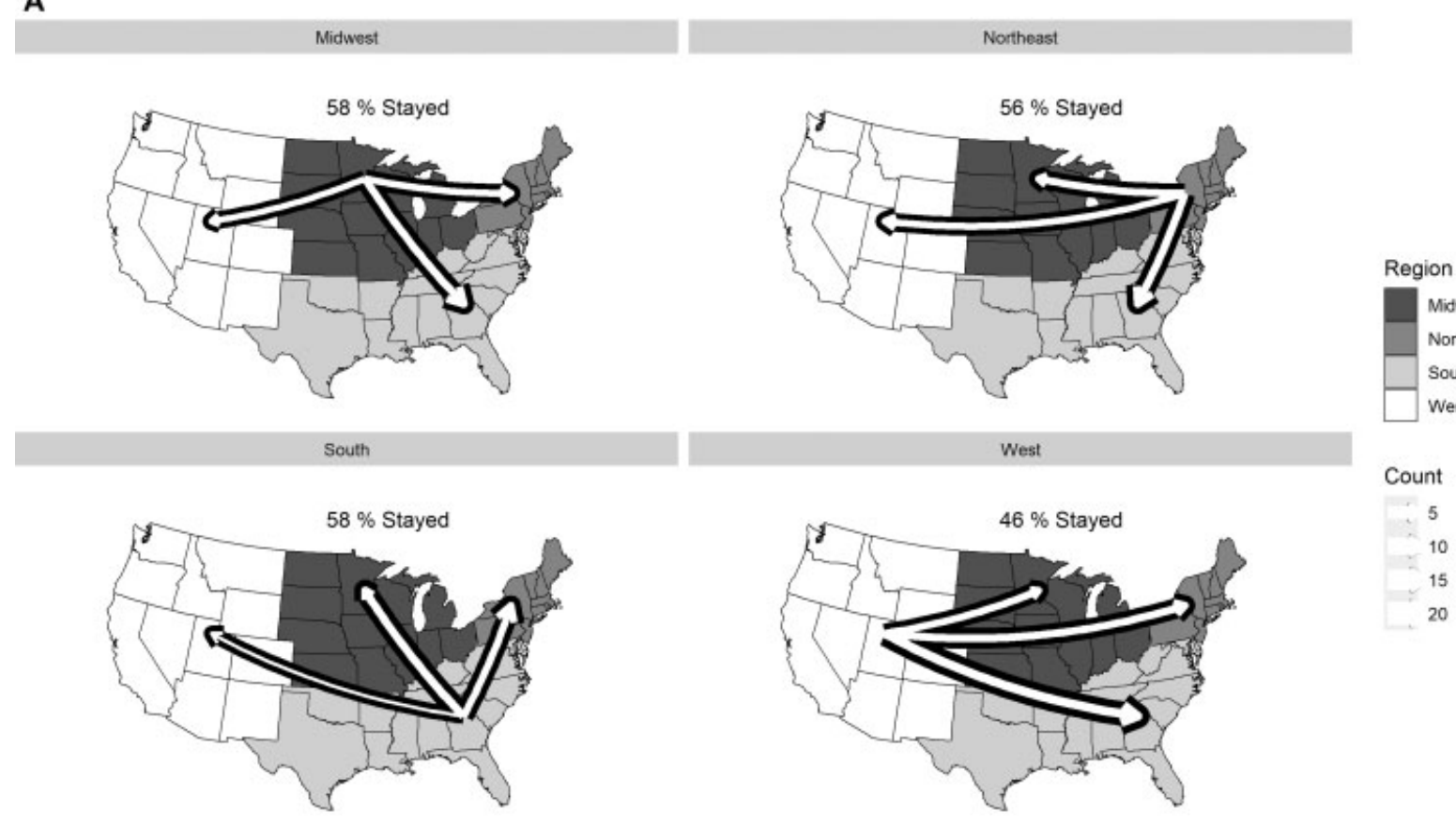

B
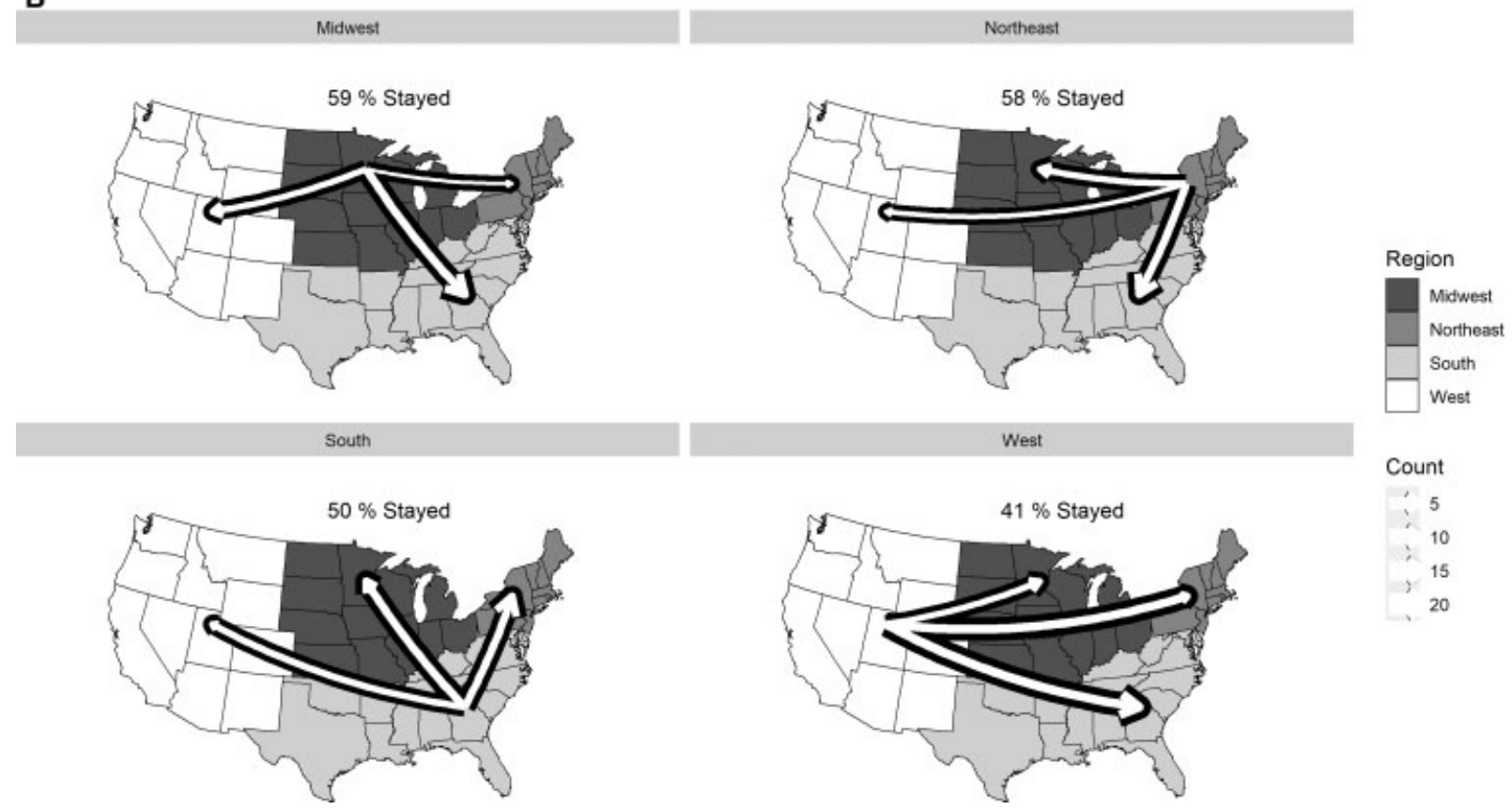

Count

, 5

5
$: 10$

15
$\square$

20

Fig. 1 (A) Distribution of students applying in 2016 to 2019 and the final region for their ophthalmology residency, stratified by region of medical school. (B) Distribution of students applying in 2020 to 2021 and the final region for their ophthalmology residency, stratified by region of medical school.

visiting student ophthalmology away rotations may be essential for medical students that aim to match at residency programs not affiliated with their medical school, especially for surgical subspecialties where over $40 \%$ of applicants matched at the site of their audition. ${ }^{10,11}$ Program directors have suggested that away rotations increased the chance of interviewing and matching at an institution. $^{12}$
This study had several limitations. Residency match data are privately stored, so this study necessarily depended on self-reported data by applicants to ophthalmology residency. A consequent limitation is that data was not collected for every applicant. Additionally, medical students may have another connection to a residency program in a different geographic region from their medical school such as attending an undergraduate university or growing up in the same 
The Impact of Virtual Interviews on the Geographic Distribution of Ophthalmology Match Results in the 2020-2021

region as the residency program, and it was not possible to fully elucidate these effects in this study, especially for the 2020 to 2021 cycle. However, there was no difference in the distribution of medical schools for applicants in the 2020 to 2021 cycle when compared with the 2016 to 2019 cycles, suggesting that the analyzed cohort sufficiently reflects characteristics of the complete cohort.

There were no differences in the overall distribution of applicants and their final residency programs when compared with their home medical schools during the 2020 to 2021 virtual interview cycle when compared with past cycles; however, there was a higher likelihood of matching at an institution associated with their home medical school. A possible solution to promote a varied distribution of residency matches in the future while maintaining virtual interviews to reduce financial burden for medical students is for the return of in-person away rotations and possible signaling mechanisms for applicants to indicate interest to certain residency programs. ${ }^{13}$ Hybrid in-person interviews and virtual interviews could also be a possibility. This option reduces the financial burden for applicants; however, they may still be compelled to attend all interviews in person if they perceive a better chance of matching with in-person interviews than virtual due to potential biases in the selection process regarding applicant interest in programs. Away rotations may enable some applicants and programs to determine if there is an appropriate fit between them. ${ }^{14,15}$ Additionally, some programs have developed virtual ophthalmology rotations during the COVID-19 pandemic and may continue to offer them in the future, which can offer more in-depth virtual opportunities for students to learn about program culture and form connections with faculty beyond virtual interviews. ${ }^{16}$ Further research including data from the 2021 to 2022 application cycle when evaluating the effects of virtual interviews combined with away rotations will provide insights into the effectiveness and feasibility of virtual interviews for future ophthalmology applicants.

Financial Support

There was no financial support for this article.

Conflicts of Interest

None declared.

\section{Acknowledgments}

None.

\section{References}

1 Quillen DA, Siatkowski RM, Feldon Sof the Association of University Professors of Ophthalmology. COVID-19 and the ophthalmology match. Ophthalmology 2021;128(02):181-184

2 Venincasa MJ, Steren B, Young BK, et al. Ophthalmology residency match in the Covid-19 Era: applicant and program director perceptions of the 2020-2021 application cycle. Semin Ophthalmol 2021;•*:1-6. Doi: 10.1080/08820538.2021.1906917

3 Association of University Professors of Ophthalmology. 2021-22 Ophthalmology Residency Match FAQs. Published 2021https:// aupo.org/sites/default/files/2021-06/Residency Match FAQs 2021.pdf. Accessed October 25, 2021

42010 Census Regions and Divisions of the United States. Published 2010. https://www.census.gov/geographies/referencemaps/2010/geo/2010-census-regions-and-divisions-of-the-united-states.html. Accessed October 25, 2021

5 R Core Team. R: a language and environment for statistical computing. Published 2017. https://www.r-project.org/.Accessed October 25, 2021

6 Fried JG. Cost of Applying to Residency Questionnaire Report: Association of American Medical Colleges. Published 2015. https://www.aamc.org/system/files/c/2/430902-costofapplyingtoresidency.pdf. Accessed October 25, 2021

7 Venincasa MJ, Cai LZ, Gedde SJ, Uhler T, Sridhar J. Current applicant perceptions of the ophthalmology residency match. JAMA Ophthalmol 2020;138(05):460-466

8 Seifi A, Mirahmadizadeh A, Eslami V. Perception of medical students and residents about virtual interviews for residency applications in the United States. PLoS One 2020;15(08): e0238239. Doi: 10.1371/journal.pone.0238239

9 Steren B, Parikh A, Ahmed B, Young B, Sridhar J, Kombo N. COVID19 and the ophthalmology residency match: data from applicants' perspectives. J Acad Ophthalmol 2021;13(01):e73-e77

10 Higgins E, Newman L, Halligan K, Miller M, Schwab S, Kosowicz L. Do audition electives impact match success? Med Educ Online 2016;21:31325. Doi: 10.3402/meo.v21.31325

11 Boyd CJ, Inglesby DC, Corey B, et al. Impact of COVID-19 on away rotations in surgical fields. J Surg Res 2020;255:96-98

12 Tso HL, Young J, Boente CS, Yung CW. The impact of away rotations on the ophthalmology residency match. J Acad Ophthalmol 2021; 13(01):e19-e25

13 Hammoud MM, Standiford T, Carmody JB. Potential implications of COVID-19 for the 2020-2021 residency application cycle. JAMA 2020;324(01):29-30

14 Prescott J. Best Practices for Conducting Residency Program Interviews. Published 2016. https://www.aamc.org/system/files/ 2020-05/best practices for conducting residency program interviews.pdf. Accessed October 25, 2021

15 Lo C, Rai A, Micieli JA. Effect of COVID-19 on Canadian Medical Student Attitudes toward Ophthalmology Residency Application. J Acad Ophthalmol 2021;13(01):e5-e10

16 Tsui E, Wells MB, Mohamed M, Felix CM, Giaconi JA. Virtual ophthalmology rotations-a real possibility during the COVID-19 pandemic and beyond. J Acad Ophthalmol 2020;12(02):e195-e199 